\title{
Body dissatisfaction and disordered eating among Portuguese and Spanish adolescents: The role of individual characteristics and internalisation of sociocultural ideals
}

\author{
Rita Francisco a , Paola Espinoza ' , Marcela L. González ${ }^{\text {b }}$, Eva Penelo ${ }^{\text {, }}$ \\ Marisol Mora ${ }^{\mathrm{b}}$, Rocío Rosés ${ }^{\mathrm{b}}$, Rosa M. Raich ${ }^{\mathrm{b}, *}$ \\ ${ }^{a}$ Faculdade de Psicologia, Universidade de Lisboa, Portugal \\ ${ }^{\mathrm{b}}$ Unitat d'Avaluació i Intervenció en Imatge Corporal, Departament de Psicologia Clínica i de la Salut, Universitat Autònoma de \\ Barcelona, Spain \\ ${ }^{\mathrm{c}}$ Laboratori d'Estadística Aplicada, Departament de Psicobiologia i Metodologia de les Ciències de la Salut, Universitat Autònoma de \\ Barcelona, Spain
}

\section{A R T I C L E I N F O}

\section{Article history:}

Available online

\section{Keywords:}

Body dissatisfaction

Disordered eating

Internalisation

Cultural differences

Gender differences

\begin{abstract}
A B S T R A C T
The aim of this study was to explore the differences in patterns of risk factors for body dissatisfaction and disordered eating attitudes in both female and male adolescents from Portugal and Spain. The sample included 455 adolescents aged $12-16$ years $(M=13.28$, $S D=0.65$ ) from two urban areas of each country. Body mass index, self-reported selfesteem, perfectionism, internalisation of sociocultural ideals, body dissatisfaction and disordered eating attitudes were assessed. Path analyses provided partial support for a cross-cultural model of body dissatisfaction and disordered eating in Western countries due to the presence of certain differences in the patterns of relationships across sex and country. The findings suggest the importance not only of identifying cultural specificities, even in "neighbouring" countries, but also of developing a global and comprehensive preventive approach that focuses on the influence of the ideal of beauty transmitted by Western societies.
\end{abstract}

(๑) 2015 The Foundation for Professionals in Services for Adolescents. Published by Elsevier Ltd. All rights reserved.

The impact of Western culture's standards of beauty on body dissatisfaction and disordered eating has been widely studied, especially among adolescents, as adolescence is a period in which individuals are more attentive to the changes that occur in their bodies. During this period, preoccupations with physical appearance frequently arise, body dissatisfaction and disordered eating to compensate for this dissatisfaction and to attain the idealised body (Levine \& Smolak, 2002). This idealised body image is usually built on the ideas of beauty spread by the society and, especially, reinforced via the media, peers and family (e.g., Bell \& Dittmar, 2011; Field et al., 2001; Stice \& Shaw, 2002). Currently, this cultural pressure is felt not only by females - requiring them to have bodies that are excessively thin and impossible for most of them to achieve (Stice \& Whitenton, 2002) - but also, and increasingly so, by males (Halliwell \& Harvey, 2006). They are asked to "build" moderately muscled and athletic bodies, and this has led to increased concern about body image and the use of weight and body shape

\footnotetext{
* Corresponding author. Unitat d'Avaluació i Intervenció en Imatge Corporal, Departament de Psicologia Clínica i de la Salut, Universitat Autònoma de Barcelona, Facultat de Psicologia, Edifici B (Campus UAB), 08193 Bellaterra (BCN), Spain. Tel.: +34 935813170 ; fax: +34 935812125.

E-mail address: rosa.raich@uab.cat (R.M. Raich).
} 
control methods among young males and a considerable prevalence of eating disorders (6.5\%; Kjelsås, Bjørnstrøm, \& Götestam, 2004), higher than previously thought (Daniel \& Bridges, 2010; Field et al., 2001; Kjelsås et al., 2004).

Our globalized society offers a complex web of forces and factors that bring people, cultures, markets, beliefs and practices into increasingly greater proximity to one another (Sorrells, 2012). In this context, Western culture and its standards of beauty are also widespread. A recent literature review revealed global patterns in terms of body dissatisfaction in different cultures associated with the process of acculturation to the Western lifestyle. For example, individuals from affluent and highly Westernised parts of Asia are more dissatisfied with their bodies than those from the USA, who in turn report greater body dissatisfaction than Europeans and Australians (Holmqvist \& Frisén, 2010). Along the same line, eating disorders have increased in populations previously considered less vulnerable to factors leading to body dissatisfaction and disordered eating, such as non-Western groups (Soh, Touyz, \& Surgenor, 2006).

Little is known, however, about cultural variations in the relative importance of risk factors for both body dissatisfaction and disordered eating. Some studies have supported the idea of a common model for Western societies, as similar patterns associated with body dissatisfaction, disordered eating, and specific risk factors have been found among adolescents and young adults (especially females) living in Western countries. For example, when comparing the tripartite influence model of body dissatisfaction and disordered eating (Thompson, Heinberg, Altabe, \& Tantleff-Dunn, 1999) among female Australian and French college students, Rodgers, Chabrol, and Paxton (2011) found very similar patterns of paths for risk factors between countries. In addition, Mautner, Owen, and Furnham (2000), comparing female college students from the United States, the United Kingdom and Italy, defended a cross-Western model, given that no cultural differences were found in the relationships between body dissatisfaction and the majority of correlates associated with body image disturbances. Similar paths, considering body mass index (BMI), weight-related teasing, body dissatisfaction and drive for thinness, were found among female adolescents from Sweden and Australia (Lunner et al., 2000).

Different biopsychosocial variables may contribute to the predisposition to body image and eating disturbances, despite the fact that no significant differences in the levels of these disturbances among the groups from diverse countries were found. For example, Sheffield, Tse, and Sofronoff (2005) confirmed that for young Australian women body dissatisfaction directly influenced eating disturbance and mediated the effects of self-esteem. In contrast, young Hong Kong women's selfesteem had a direct effect on eating disturbance, but body dissatisfaction was not a significant predictor for eating disturbance. Tiggemann, Verri, and Scaravaggi (2005) also found the consumption of fashion magazines to be a predictor among Australian young women but not among Italians. However, studies that focus specifically on different samples of European countries are scarce. Are Western European countries similar in relation to how adolescents are affected by the pressures of prevailing beauty models? Do the risk factors for body image dissatisfaction and eating disorders relate equally between them, considering that the values and customs influence social and gender roles, aesthetic preferences and eating habits (Privitera, 2008)?

Most of the cross-cultural studies that focus on differences in the models of risk factors for body image and eating disorders have been conducted with female adolescents or female college students (an example of an exception being Kayano et al., 2008), due in part to the lower prevalence of eating disorders among males (Striegel-Moore \& Bulik, 2007). It has been assumed basically that the same factors could contribute to body dissatisfaction and disordered eating among boys and girls (Keel, Klump, Leon, \& Fulkerson, 1998; Ricciardelli \& McCabe, 2004). However, it is now thought that important differences may exist and should be investigated (Presnell, Bearman, \& Stice, 2004). The present study aims to compare a proposed model of risk factors for body dissatisfaction and disordered eating among female and male adolescents from two "neighbouring" southern-European countries, Portugal and Spain. These two countries share many characteristics, but according to the cultural dimensions considered by Hofstede (2001), they differ notably with respect to individualism (vs. collectivism) and masculinity (vs. femininity). In fact, Spain shows higher values on these both dimensions compared to Portugal (Hofstede, Hofstede, \& Minkov, 2010), so the self-image of Spanish individuals is defined more in terms of "I" than "We." They are also more self-centred and focused on material and individual achievements. These differences can be related to gender roles and aesthetic preferences in each country, so we think it is important to compare these two countries using a byopsychossocial model of risk factors for body dissatisfaction and eating disorders.

Because the development of body image and eating disorders is considered a multifactorial process, individual biological and psychological contributions to body image and disordered eating need to be considered, as well as sociocultural factors (Jones, Vigfusdottir, \& Yoonsun, 2004; Lawler \& Nixon, 2011). Thus, in the present study, besides considering the internalization of the sociocultural ideals of beauty, we also introduced BMI as an important variable and two other individual characteristics considered important risk factors for body dissatisfaction and disordered eating: perfectionism and selfesteem (see Fig. 1).

\section{BMI, self-esteem and perfectionism}

Body weight has been considered an important factor in predicting body image disturbance for both adolescent males and females (Stice \& Whitenton, 2002), although the strength of the relationships seems to vary by gender (Jones et al., 2004; Lawler \& Nixon, 2011). Body weight can also indirectly predict disordered eating, as individuals with a higher BMI and a greater deviation from the sociocultural ideal may engage in extreme dieting behaviours to control their weight (Stice \& Shaw, 2002). On the other hand, adolescents with low self-esteem may be more predisposed to develop body dissatisfaction and disordered eating (e.g., Francisco, Narciso, \& Alarcão, 2013; Ricciardelli \& McCabe, 2004; Stice, Presnell, \& Spangler, 


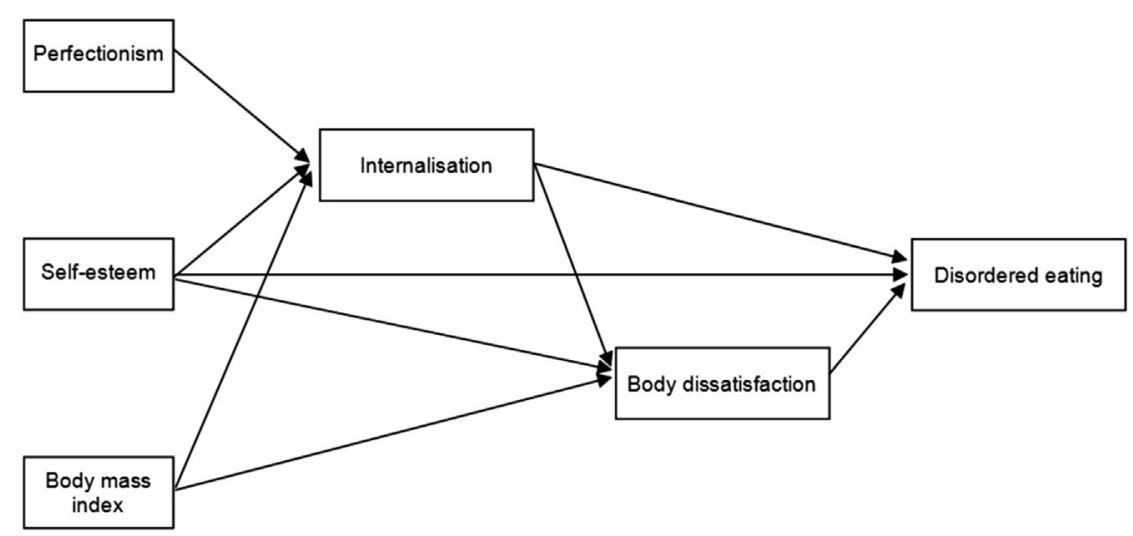

Fig. 1. Hypothesized path model for Spanish and Portuguese adolescents' body dissatisfaction and disordered eating

2002), as dieting or other eating behaviours may result from a desire to increase self-esteem by increasing satisfaction with weight or body shape (Sheffield et al., 2005). Perfectionism may predispose individuals to the development of disordered eating (Boone, Soenens, Vansteenkiste, \& Braet, 2012; Forbush, Heatherton, \& Keel, 2007) and eating disorders (Bulik et al., 2003), although some studies did not found this association (Gustafsson, Edlund, Kjellin, \& Norring, 2009) or found weak correlations between them (Francisco, Alarcão, \& Narciso, 2011).

\section{The mediating role of internalization on both body dissatisfaction and disordered eating}

Both boys and girls are affected by sociocultural body ideals, although the effect seems to be greater for girls (Smolak, Levine, \& Thompson, 2001). As suggested in the tripartite influence model, the effect of influences from the media, parents and peers is mediated by the internalisation of social ideals and social comparison, leading to body dissatisfaction, disordered eating and negative affect (J. Thompson et al., 1999). Internalisation may directly contribute to body dissatisfaction for all adolescents (Jones et al., 2004; Lawler \& Nixon, 2011), while the discrepancy between a person's ideal and actual body image is believed to cause body distress and dissatisfaction (Stice \& Whitenton, 2002). However, some studies have supported a gender-moderated effect of the internalisation of sociocultural ideals on body dissatisfaction and disordered eating. For example, Knauss, Paxton, and Alsaker (2008) reported that internalisation directly predicted body dissatisfaction among girls, but not among boys.

In the present study, we hypothesize that perfectionism would influence body dissatisfaction and disordered eating indirectly by increasing susceptibility to the internalisation the sociocultural ideal (Keel \& Forney, 2013; Striegel-Moore \& Bulik, 2007). In addition, BMI and self-esteem (besides the possible direct influence of these variables on disordered eating) are hypothesized as risk factors for body dissatisfaction and for disordered eating through their influence on internalisation, as previous research suggests (Stice \& Shaw, 2002).

\section{The mediating role of body dissatisfaction on disordered eating}

The strong association between body dissatisfaction and disordered eating is well documented, as body dissatisfaction is one of the most relevant risk factors, predictors and DSM-IV criteria for eating disorders (American Psychiatric Association, 2000; Levine \& Smolak, 2002; Striegel-Moore \& Bulik, 2007). However, body dissatisfaction is also frequently found as an important mediator in the development of disordered eating, considering different independent variables, such as ideal-body stereotype internalisation (Stice, Schupak-Neuberg, Shaw, \& Stein, 1994), BMI (Stice \& Shaw, 2002) or self-esteem (Sheffield et al., 2005). We hypothesize in this study that body dissatisfaction will mediate the effects of three biopsychosocial risk factors (BMI, self-esteem and internalization of sociocultural ideal) on eating disturbance in Portuguese and Spanish adolescents.

\section{Study overview}

The present study aims to evaluate the equivalence for a proposed model of potential risk factors for body dissatisfaction and disordered eating among female and male adolescents from two neighbouring southern-European countries, Portugal and Spain.

Thus, the objectives are three-fold: a) to examine the contributions of BMI, perfectionism, self-esteem, and internalisation of sociocultural ideals to body dissatisfaction and disordered eating in Portuguese and Spanish adolescents of both sexes; b) to verify the mediating role of internalisation of sociocultural ideals on body dissatisfaction and disordered eating, as well as the mediating role of body dissatisfaction on disordered eating; and c) to determine the equivalence of these associations of 
biopsychosocial risk factors across sex and country. We expected the proposed model to show equivalent paths across Portuguese and Spanish adolescents of the same sex, but non-equivalent ones across female and male groups. However, given the inconsistency of the findings in the literature reviewed, the direction of this non-equivalence was unspecified.

\section{Method}

Participants

The study involved 455 adolescents of both sexes, aged $12-16$ years: 206 from Portugal $(M=13.65$ years, $S D=0.78 ; 50.5 \%$ females) and 249 from Spain $(M=13.39$ years, $S D=0.51 ; 51.8 \%$ females). Most of the participants (46.2\%) were of medium-high/high socioeconomic status (SES; Hollingshead, 2011), while 29\% and 24.8\% were of medium-low and low SES; no differences were observed across sex within each country (Portugal: $\chi^{2}=0.21, p=.899 ;$ Spain: $\chi^{2}=1.25, p=.536$ ).

\section{Measures}

Table 1 (left) presents the internal consistency and range for self-reported composite scores (see below) in the study sample.

Body mass index (BMI)

Measurements of weight and height were collected, and BMI was calculated. These were self-reported in Portugal and made in situ individually and privately by two members of the research team in Spain.

\section{Self-esteem}

We used the 10-item Rosenberg Self-Esteem Scale (RSES; Rosenberg, 1965), in which higher scores indicate a higher selfesteem (e.g., "I feel that I am a person of worth, at least on an equal plane with others"). The Portuguese (Azevedo \& Faria, 2004; $\alpha=.89$ ) and the Spanish (Baños \& Guillén, 2000; $\alpha=.86$ ) versions, validated with adolescent populations, were used.

\section{Perfectionism}

We used the 6-item (e.g., "I hate being less than best at things") perfectionism subscale of the Eating Disorder Inventory-2 (EDI-2; Garner, 1991), in which higher scores indicate more perfectionism. The Portuguese (Pocinho, 2000; $\alpha=.63$ ) and the Spanish (Garner, 1998; $\alpha=.83$ ) versions were used.

\section{Internalisation of sociocultural ideals of beauty}

The 10-item subscale Internalisation of the Sociocultural Attitudes Towards Appearance Questionnaire-R (SATAQ-R; Cusumano \& Thompson, 1997) was used to assess the internalisation of body stereotypes in the popular media (e.g., "I would like my body to look like the bodies of people in the movies"). Higher scores are indicative of a greater internalisation of sociocultural ideals of beauty. The Portuguese (Francisco, Santos, Oliveira, \& Novo, 2011; $\alpha=.88$ ) and the Spanish (Calado, $2008 ; \alpha=.89$ ) versions were used.

Body dissatisfaction

The Contour Drawing Rating Scale (CDRS; M. Thompson \& Gray, 1995) was used to assess adolescents actual and ideal sizes. The CDRS is one of the most used, useful, and easily administered figure-drawing rating scales (Wertheim, Paxton, \&

Table 1

Descriptive statistics, measures internal consistency, and inter-correlations by country and sex $(N=455)$.

\begin{tabular}{|c|c|c|c|c|c|c|c|c|c|c|c|}
\hline \multirow[t]{2}{*}{ Country } & \multirow[t]{2}{*}{ Measure $($ minimum $\div$ maximum $)$} & \multicolumn{2}{|l|}{ Alpha } & \multicolumn{2}{|l|}{$M(S D)$} & \multicolumn{6}{|c|}{ Pearson's correlations } \\
\hline & & Females & Males & Females & Males & 1 & 2 & 3 & 4 & 5 & 6 \\
\hline \multirow[t]{6}{*}{ Spain } & 1. Body mass index & & & $20.25(3.03)$ & $20.55(3.73)$ & - & $-.40^{* * *}$ & -.05 & $.19^{*}$ & $.56^{* * *}$ & $.24^{*}$ \\
\hline & 2. RSES Self esteem $(10 \div 40)$ & .83 & .79 & $29.33(5.36)$ & $32.08(4.81)$ & -.10 & - & -.05 & $-.54^{* * *}$ & $-.49^{* * *}$ & $-.57^{* * *}$ \\
\hline & 3. EDI-2 Perfectionism $(0 \div 18)$ & .71 & .58 & $4.52(3.68)$ & $4.88(3.39)$ & .05 & -.05 & - & .09 & .08 & .14 \\
\hline & 4. SATAQ-R Internalisation $(1 \div 5)$ & .86 & .77 & $2.93(0.86)$ & $2.55(0.77)$ & .12 & $-.51^{* * *}$ & $.30^{* * *}$ & - & $.32^{* * *}$ & $.43^{* * *}$ \\
\hline & 5. CDRS Body dissatisfaction $(-8 \div 8)$ & - & - & $0.81(1.50)$ & $0.57(1.20)$ & $.43^{* * *}$ & $-.35^{* * *}$ & .06 & $.30^{* * *}$ & - & $.40^{* * *}$ \\
\hline & 6. EAT-26 Eating attitudes $(0 \div 78)$ & .89 & .90 & $8.20(9.18)$ & $5.51(8.46)$ & .12 & $-.50^{* * *}$ & $.38^{* * *}$ & $.47^{* * *}$ & $.39^{* * *}$ & - \\
\hline \multirow[t]{6}{*}{ Portugal } & 1. Body mass index & & & $20.29(2.96)$ & $20.34(3.40)$ & - & -.01 & .05 & .08 & $.70^{* * *}$ & .03 \\
\hline & 2. RSES Self esteem $(10 \div 40)$ & .86 & .79 & $29.68(6.69)$ & $31.84(5.28)$ & -.13 & - & .05 & $-.33^{* * *}$ & -.03 & $-.29^{* *}$ \\
\hline & 3. EDI-2 Perfectionism $(0 \div 18)$ & .68 & .67 & $6.69(3.83)$ & $6.85(3.88)$ & .03 & -.08 & - & -.02 & -.07 & -.03 \\
\hline & 4. SATAQ-R Internalisation $(1 \div 5)$ & .87 & .75 & $2.94(0.94)$ & $2.61(0.70)$ & $.28^{* *}$ & $-.54^{* * *}$ & .07 & - & .11 & .14 \\
\hline & 5. CDRS Body dissatisfaction $(-8 \div 8)$ & - & - & $0.68(1.34)$ & $0.34(1.16)$ & $.56^{* * *}$ & $-.21^{*}$ & -.08 & $.40^{* * *}$ & - & -.04 \\
\hline & 6. EAT-26 Eating attitudes $(0 \div 78)$ & .90 & .84 & $12.05(11.03)$ & $8.69(8.82)$ & $.25^{* *}$ & $-.44^{* * *}$ & .01 & $.58^{* * *}$ & $.46^{* * *}$ & - \\
\hline
\end{tabular}

For Pearson's correlations, values for females are in the lower-left triangle and values for males are in the upper-right triangle.

${ }^{*} p<.05 ;{ }^{* *} p<.01 ;{ }^{* * *} p<.001$ 
Tilgner, 2004). It comprises nine male and nine female contour drawings numbered from one to nine, from severely underweight to extremely obese. The participants are asked to select the figure that most closely approximates their current body (current size) and the figure that they would most like to resemble (ideal size). The discrepancy between the ideal and current size scores was used as an index of body size dissatisfaction (Wertheim et al., 2004), which can range from 8 (extreme desire to lose weight) to -8 (extreme desire to gain weight). The Portuguese (Francisco, Narciso, \& Alarcão, 2012) and an ad hoc version translated into Spanish were used, which present good convergent validity: correlations of the silhouette representing current body size with weight $r=.65$ and with BMI $r=.72$ for the Portuguese version and $r=.58$ and $r=.62$ for the Spanish version, respectively.

\section{Disordered eating attitudes}

The total score of the Eating Attitudes Test (EAT-26; Garner, Olmsted, Bohr, \& Garfinkel, 1982) was used to assess a wide range of attitudes and behavioural characteristics associated with disordered eating. Higher scores of the total of 26 items (e.g., "I feel that food controls my life") are indicative of more dysfunctional eating attitudes. The Portuguese (Francisco, Oliveira, Santos, \& Novo, 2011; $\alpha=.91$ ) and the Spanish (Gandarillas, Zorrilla, Sepúlveda, \& Muñoz, 2003; $\alpha=.86$ ) versions were used.

\section{Procedure}

Participants were recruited from four urban state and state-subsidised schools from the Lisbon Metropolitan Area (Portugal) and seven from Manresa, located in the Barcelona area (Catalonia, Spain), and selected by means of incidental (non-random) sampling during 2011. Formal authorisations were obtained from each school, from the Portuguese Ministry of Education, from the Municipal Institute of Health and Social Welfare of the city of Manresa, and from the Ethics Committee of the authors' universities. Written authorisation from the parents and informed consent forms from the students were also obtained. Participants completed the surveys during normal classes at their schools in the presence of their teachers and a research assistant. All of the students whose parents had already provided informed consent agreed to participate. Each student took approximately $20 \mathrm{~min}$ to complete the survey. Participation in the study was completely voluntary, and no compensation was provided to the participants.

\section{Statistical analysis}

The statistical analyses were carried out with Mplus7 (Muthén \& Muthén, 1998-2012). Multi-group Structural Equation Modelling (SEM) was conducted using the Robust Maximum Likelihood (MLR) method of estimation, which is robust to nonnormality for continuous dependent variables. It is also a full-information method (Enders \& Bandalos, 2001; Graham, 2009). Goodness-of-fit was assessed using the common fit indices: scaled $\chi^{2}$ and $p$ values, the Comparative Fit Index (CFI), the Tucker-Lewis Index (TLI), and the Root Mean Square Error of Approximation (RMSEA). Reasonable and adequate model fits were considered for the non-significant chi-square test $(p>.05)$, CFI and TLI above .90 or .95 , and RMSEA below .08 or .06 , respectively (Hu \& Bentler, 1999). We used a multi-group approach. Firstly, a baseline model for the whole sample was established with all parameters freely estimated across the four groups (sex $\times$ country). Then, invariance for paths across groups was tested using the scaled chi-square difference (Bryant \& Satorra, 2012) for nested models ( $\alpha$ level set at .05).

\section{Results}

The means, standard deviations, and inter-correlations between the variables for each group are shown in Table 1, which also includes internal consistency measures for each composite measure in the present sample. From 455 initial participants, data for 10 individuals were excluded (one for each group, except for Spanish males with seven cases discarded) because they had missing values for one of the independent variables (BMI, RSES Self-esteem, EDI-2 Perfectionism). Thus, and given that missing values in any variable accounted for less than $5 \%$ of cases (2.2\%), listwise deletion was applied (Graham, 2009).

The goodness-of-fit indices for the baseline multi-group model (configural model) we established considering the whole sample were acceptable $\left[\chi^{2}(12)=18.412, p=.104 ; \mathrm{CFI}=.983, \mathrm{TLI}=.933\right.$, RMSEA $\left.=.069\right]$. When fixing all parameters to be equivalent across the four groups, complete equivalence was not achieved $\left[\Delta \chi^{2}(27)=43.898, p=.021\right]$. After freeing three parameters across some groups one at time based on modification indices, partial equivalence was attained $\left[\Delta \chi^{2}\right.$ $(24)=30.044, p=.183]$. This final model showed a satisfactory fit $\left[\chi^{2}(36)=48.690, p=.077 ; \mathrm{CFI}=.967, \mathrm{TLI}=.956\right.$, RMSEA $=.056]$.

The non-equivalent direct paths were as follows: SATAQ-R Internalisation on EDI-2 Perfectionism was only positive and statistically significant for Spanish females, whereas it was null and equivalent across the remaining three groups; CDRS-Body dissatisfaction on RSES Self-esteem was non-equivalent across country, being negative for Spanish participants and null for Portuguese participants; and CDRS-Body dissatisfaction on SATAQ-R Internalisation was non-equivalent across sex, being positive for females and null for males. The remaining direct paths were all statistically significant $(p<.05)$ and equivalent across the four groups of adolescents: higher self-esteem was mainly related to lower SATAQ-R Internalisation and also moderately related to lower EAT-Disordered eating attitudes, whereas BMI was mainly positively related to CDRS-Body dissatisfaction and to a lesser extent to SATAQ-R Internalisation. Paths for EAT-Disordered eating attitudes on both CDRS- 
Body dissatisfaction and SATAQ-R Internalisation were positive but moderate. Fig. 2 shows standardised regression weights for each structural path for all of the aforementioned direct effects and the explained variance (R-square) for each dependent (endogenous) variable of the final model, which will be considered later.

Table 2 details parameters for non-equivalent effects across country and sex, and complete estimations and significance levels for direct, indirect and total effects are displayed in Table S1. Regarding indirect effects, the non-equivalent direct paths across some groups yielded the following different indirect effects: EAT-Disordered eating attitudes on Perfectionism via SATAQ-R Internalisation and CDRS-Body dissatisfaction was statistically significant only for Spanish females, and CDRS-Body dissatisfaction on RSES Self-esteem via SATAQ-R Internalisation was statistically significant only for females from both countries. Finally, non-statistically indirect effects were found in all groups for EAT-Disordered eating attitudes on RSES Selfesteem (via SATAQ-R Internalisation) and EAT-Disordered eating attitudes on BMI (via SATAQ-R Internalisation and CDRSBody dissatisfaction).

The explained variance of internalisation of sociocultural ideals (SATAQ-R Internalisation) was slightly higher for Spanish (approximately 30\%) than for the Portuguese (almost 25\%) adolescents, to which self-esteem (and perfectionism, for Spanish girls) and BMI especially contributed. Variance explained for CDRS-Body dissatisfaction was higher for males (48\% Spanish and 39\% Portuguese), to which BMI contributed strongly (and self-esteem for Spanish males), than for females (almost 30\%), to whom internalisation of sociocultural ideals also contributed. Lastly, the explained variance of EAT-Disordered eating attitudes was similar for both Spanish and Portuguese females and Spanish males (approximately 30\%), but lower for Portuguese males (20\%) (Fig. 2, in italics).

\section{Discussion}

The present study aimed to evaluate the equivalence for a proposed model of potential risk factors for body dissatisfaction and disordered eating among female and male adolescents from Portugal and Spain. As expected, the final multi-group model showed a similar pattern of risk factors, as all paths except three were equivalent across sex and country. For all adolescents, higher self-esteem was mainly related to lower internalisation of the sociocultural ideal and also moderately to lower disordered eating attitudes, whereas BMI was mainly positively related to body dissatisfaction and to a lesser extent to internalisation of the sociocultural ideal. Additionally, paths for disordered eating attitudes on both body dissatisfaction and internalisation of the sociocultural ideal were positive but moderate.

Firstly, lower self-esteem was only significantly predictive of body dissatisfaction among Spanish adolescents, despite being considered a direct predictor of disordered eating for all adolescents. These findings are in line with those of Sheffield et al. (2005), who reported that for Hong Kong females (but not for Australian females) self-esteem was not predictive of body dissatisfaction. For Portuguese adolescents, sociocultural ideals probably need to have been internalised (and a comparison made with it) in order for these individuals to feel dissatisfied with the body. In this way, we can hypothesise that for the Spanish sample physical appearance is a highly important dimension of self-concept, as low general self-esteem can lead to low body self-esteem (or body dissatisfaction), without these individuals necessarily having internalised the ideals proposed by their society. For the Portuguese sample, the results indicate that those who have engaged the sociocultural ideal and have converted it into a priority are dissatisfied with their bodies. However, for the whole sample, presenting low self-esteem seems to lead to disordered eating, probably by attempting to improve the former by means of diets or other maladaptive types of eating behaviour. In addition, the mediating role of body dissatisfaction between self-esteem and disordered eating was not confirmed for the whole sample, contrary to some previous studies (Sheffield et al., 2005). Thus, dieting may result from a desire to increase self-esteem but not necessarily by increasing satisfaction with body shape or weight.

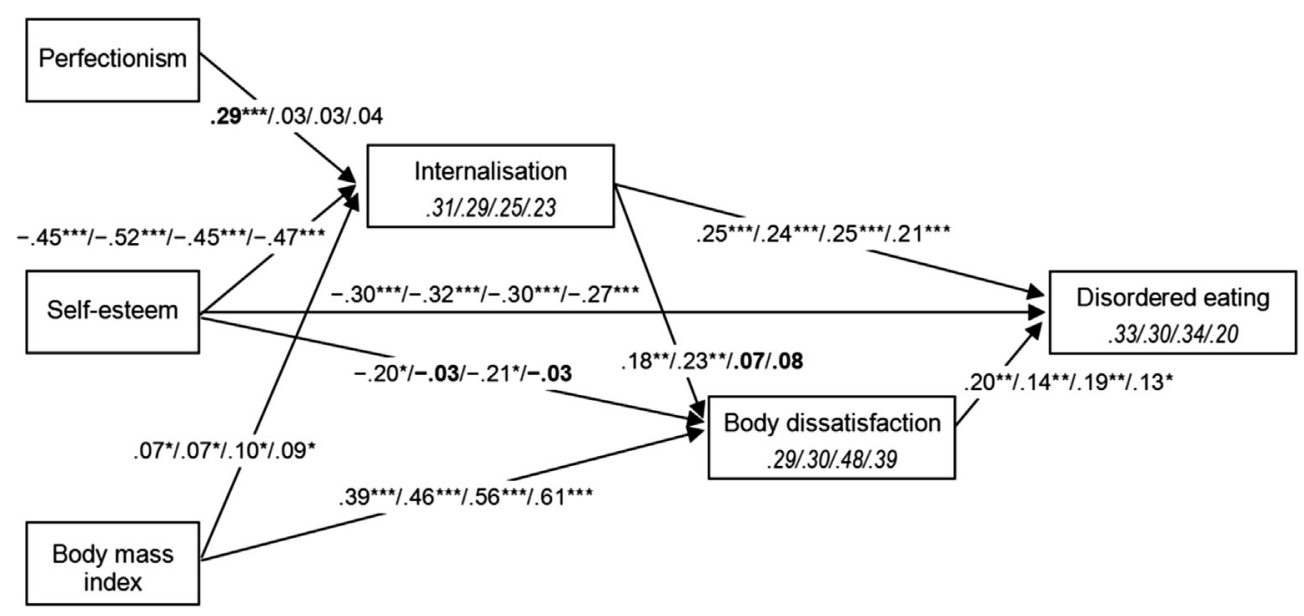

Fig. 2. Final multi group model for Spanish females/Portuguese females/Spanish males/Portuguese males: Standardised path coefficients and explained variance for dependent variables (R-square, in italics). In bold: paths non-equivalent across some groups. Note: ${ }^{*} p<.05$; ${ }^{* *} p<.01 ;{ }^{* * *} p<.001$. 
Table 2

Unstandardised and standardised indirect effects (and significance level) for non-equivalent direct effects across country and sex.

\begin{tabular}{|c|c|c|c|c|c|c|c|c|c|c|c|}
\hline \multirow[t]{2}{*}{ X-Variable } & \multirow[t]{2}{*}{ Y-Variable } & \multirow[t]{2}{*}{ Mediator } & \multirow[t]{2}{*}{ Differences } & \multicolumn{4}{|c|}{ Unstandardised effects ( $p$-value) } & \multicolumn{4}{|c|}{ Standardised effects ( $p$-value) } \\
\hline & & & & Female-Sp & Female-Pt & Male-Sp & Male-Pt & Female-Sp & Female-Pt & Male-Sp & Male-Pt \\
\hline BMI & Body dissatisfaction & Intern & None & $0.006(.070)$ & $0.006(.070)$ & $0.002(.300)$ & $0.002(.300)$ & $.013(.073)$ & $.015(.071)$ & $.006(.290)$ & $.007(.297)$ \\
\hline BMI & red eating & $\begin{array}{l}\text { Internalisation; Body } \\
\text { dissatisfaction }\end{array}$ & None & $0.007(.139)$ & $0.007(.139)$ & $0.003(.357)$ & $0.003(.357)$ & $.002(.134)$ & $.002(.140)$ & $.001(.343)$ & .001 \\
\hline Perfe & on & Internalisation & $\mathrm{p}>$ rest & 0.02 & 0.00 & & & 08) & .00 & .002 & .003 \\
\hline Perfectionism & Disordered eating & Internalisation & Female-Sp $>$ rest & $0.176(.002)$ & $0.020(.498)$ & $0.020(.498)$ & $0.020(.498)$ & $.072(.002)$ & $.007(.501)$ & .008 (.499) & $.008(.500)$ \\
\hline Perfectionism & Disordered eating & $\begin{array}{l}\text { Internalisation, Body } \\
\text { dissatisfaction }\end{array}$ & Female-Sp > rest & $0.024(.044)$ & $0.003(.514)$ & $0.001(.557)$ & $0.001(.557)$ & $.010(.038)$ & $.001(.516)$ & $.001(.551)$ & $.001(.558)$ \\
\hline Self-e & Body dissatisfaction & Internalisation & Females $>$ Males & $-0.023(<.001)$ & $-0.023(<.001)$ & $-0.008(.224)$ & $-0.008(.224)$ & $-.080(.001)$ & $-.119(.001)$ & $-.030(.212)$ & $-.038(.222)$ \\
\hline Self-esteem & Disordered eating & Body dissatisfaction & None & $-0.067(.141)$ & $-0.006(.709)$ & $-0.067(.141)$ & $-0.006(.709)$ & $-.040(.127)$ & $-.004(.708)$ & $-.039(.127)$ & $-.003(.711)$ \\
\hline
\end{tabular}

In bold: indirect effects statistically significant. 
Secondly, perfectionism was only a significant predictor of the internalisation of sociocultural ideals for Spanish girls. In addition, the indirect effects of perfectionism, influencing body dissatisfaction by means of internalisation and influencing disordered eating by means of internalisation and body dissatisfaction, were all significant only for Spanish female adolescents and null for the remaining three groups. These results as to the Spanish females are in accordance with various studies that consider perfectionism as an important personality trait that can predispose adolescents to body dissatisfaction and disordered eating, especially by increasing their susceptibility to internalising the sociocultural ideal or by influencing the selection of the peer environment (Keel \& Forney, 2013; Striegel-Moore \& Bulik, 2007). Is it possible that Spanish society puts greater demands on their female citizens for accept and follow sociocultural ideal? This pressure could be related to a greater exposure to globalisation and mass media through the Internet, which have a significant impact on eating attitudes and behaviours, particularly among young people (Anderson-Fye, 2009). In the last several years, the numbers of worldwide Internet users has grown exponentially. Although the total portion of internet users Europe has reached 75\% of the population, the percentage of Portugal's population that are Internet users has reached only 64\%, whereas this figure in Spain is $72 \%$ (European Commission, 2013). On the other hand, the higher focus on individual goals and self-image among the Spanish population, compared to the Portuguese one (Hofstede et al., 2010), also could explain these results and should be investigated in the future. The results of the other three groups are in accordance with other studies (Gustafsson et al., 2009) and strengthen the need to consider the different dimensions of perfectionism, as noted by Wade and Tiggemann (2013), and cross-cultural and gender differences. For example, a study with Portuguese adolescents reported that in both genders socially prescribed perfectionism was a useful predictor of disordered eating but that self-oriented perfectionism should not be considered a predictor of eating behaviours in boys (Bento et al., 2010). In addition, although conducted with adults, a recent study (Downey, Reinking, Gibson, Cloud, \& Chang, 2014) showed that daily perfectionistic thoughts mediated the relationships between both self-oriented and socially prescribed perfectionism and dieting behaviour among women. However, among men the increased perfectionistic thinking only mediated the relationship between self-oriented perfectionism and bulimic (but not dieting) behaviour. From a sociocultural point of view, females and males might seek perfection by dieting or consuming greater amounts of food, respectively, to attain the ever-slimmer female body ideal and the large and muscular male body ideal.

Thirdly, internalisation of sociocultural ideals directly predicted body dissatisfaction among females, but not among males. However, this result is in accordance with previous studies, which argued that females respond with greater intensity to body ideals and, consequently, experience greater body dissatisfaction than boys (Knauss et al., 2008). On the other hand, BMI directly predicted body dissatisfaction and internalisation of sociocultural ideals for all groups, with the latter showing weaker values. These findings partially contradict previous studies evidencing no such relationship between BMI and internalisation among both female and male adolescents (Lawler \& Nixon, 2011). However, Jones et al. (2004) also found BMI to be a predictor of body dissatisfaction among similar samples. Interestingly, the mediating role of internalisation between BMI and body dissatisfaction was not statistically significant for any of our groups, in contrast to previous studies (Stice \& Shaw, 2002). In this sense, subjective factors probably interact and have influence in this process, despite the real weight, and should be investigated in the future.

Considering the results of the proposed model as a whole, the included variables explained a higher percentage of variance of males' body dissatisfaction than that of female adolescents. In addition, the lower explained variance of disordered eating among Portuguese males lead us to consider the need to evaluate other variables (e.g., social comparison, negative affect) in future studies and to highlight the need to understand in depth the risk factors specifically associated with disordered eating among females and males, as well as among adolescents from different countries or cultures. However, the confirmed role of internalisation and body dissatisfaction in the proposed model of risk factors for disordered eating reinforces the fact that preventive interventions, widely developed across different cultures, should focus on these variables (e.g., Espinoza, Penelo, \& Raich, 2013; González, Penelo, Gutiérrez, \& Raich, 2011). However, because of the cultural differences found regarding these mediating effects, the prevention programmes should be empirically validated in each country before being widely adopted, to take into account the specificities of each target population.

Future research should include other sociocultural variables, such as critical comments about the body from peers and parents, values about individualism and collectivism, etc. In addition, the deep understanding of the development of body dissatisfaction and disordered eating among adolescents from different cultures would benefit from further longitudinal and experimental research aimed at clarifying the factors that put female and male adolescents at risk.

The present study has some potential limitations that need to be recognised, especially the cross-sectional nature of the design. Secondly, despite the convenient nature of both samples, there were differences in the data collection procedure for Spanish and Portuguese samples, specifically in terms of weight and height, which in Portugal were self-reported. However, several studies have revealed high correlations between weight and height, both when self-reported and when measured by researchers (Bulik et al., 2001). Thirdly, the variables were assessed solely from the adolescents' perspective, despite that it would be important to consider other sources of information, such as peers and parents, who are also important sources of sociocultural influence on body dissatisfaction and disordered eating (Field et al., 2001). Finally, two other limitations are related to some of the measures used: CDRS could not be the best choice to assess body dissatisfaction in males (given the muscular and athletic appearance ideal for males) because this measure may confound body fat level with muscularity (Frederick et al., 2007); the perfectionism measure (EDI-2 subscale) presents moderate internal consistency, especially in Spanish male sample, only satisfactory for research. 
Despite these limitations, the present research expands on previous studies by exploring a model of potential risk factors for body dissatisfaction and disordered eating among two Southern European samples. These findings provide partial support for a common model of body dissatisfaction and disordered eating for Western countries, due to the presence of certain differences in paths across sex and country.

\section{Acknowledgements}

This study was partially supported by grants SEJ2005-07099 from the Ministry of Science and Technology, PSI2010-22067 from the Ministry of Economy and Competitiveness, 2009-SGR-1450 from the Catalan Government (Spain), and PEst-OE/PSI/ UI0314/2014 from the Ministry of Science and Technology (FCT, Portugal). We would like to express our appreciation to the participating schools.

\section{Appendix A. Supplementary data}

Supplementary data related to this article can be found at http://dx.doi.org/10.1016/j.adolescence.2015.02.004.

\section{References}

American Psychiatric Association. (2000). Diagnostic and statistical manual of mental disorders (4th ed.). Washington, DC: American Psychiatric Association.

Anderson-Fye, E. (2009). Cross-cultural issues in body image among children and adolescents. In L. Smolak, \& J. K. Thompson (Eds.), Body image, eating disorders and obesity in youth (pp. 113-133). Washington: American Psychological Association.

Azevedo, Â. S., \& Faria, L. (2004). A auto-estima no ensino secundário: Validação da Rosenberg Self-Esteem Scale. In C. Machado, L. S. Almeida, M. Gonçalves, \& V. Ramalho (Eds.), Actas da X conferência internacional de avaliação psicológica: Formas e contextos (Vol. X, pp. 415-421). Braga: Psiquilíbrios Edições.

Baños, R. M., \& Guillén, V. (2000). Psychometric characteristics in normal and social phobic samples for a Spanish version of the Rosenberg Self-Esteem Scale. Psychological Reports, 87, 269-274. http://dx.doi.org/10.2466/pr0.2000.87.1.269.

Bell, B. T., \& Dittmar, H. (2011). Does media type matter? The role of identification in adolescent girls' media consumption and the impact of different thinideal media on body image. Sex Roles, 65, 478-490. http://dx.doi.org/10.1007/s11199-011-9964-x.

Bento, C., Pereira, A. T., Maia, B., Marques, M., Soares, M. J., Bos, S., et al. (2010). Perfectionism and eating behaviour in Portuguese adolescents. European Eating Disorders Review, 18, 328-337. http://dx.doi.org/10.1002/erv.981.

Boone, L., Soenens, B., Vansteenkiste, M., \& Braet, C. (2012). Is there a perfectionist in each of us? An experimental study on perfectionism and eating disorder symptoms. Appetite, 59, 531-540. http://dx.doi.org/10.1016/j.appet.2012.06.015.

Bryant, F. B., \& Satorra, A. (2012). Principles and practice of scaled difference chi-square testing. Structural Equation Modeling: A Multidisciplinary Journal, 19, 372-398. http://dx.doi.org/10.1080/10705511.2012.687671.

Bulik, C., Tozzi, F., Anderson, C., Mazzeo, S., Aggen, S., \& Sullivan, P. (2003). The relation between eating disorders and components of perfectionism. The American Journal of Psychiatry, 160, 366-368. http://dx.doi.org/10.1176/appi.ajp.160.2.366.

Bulik, C., Wade, T., Heath, A., Martin, N., Stunkard, A., \& Eaves, L. (2001). Relating body mass index to figural stimuli: population-based normative data for Caucasians. International Journal of Obesity and Related Metabolic Disorders, 25(10), 1517-1524.

Calado, M. (2008). Influence of the mass media on body image and disordered eating in secondary school students (Unpublished doctoral dissertation). Ourense: University of Vigo.

Cusumano, D., \& Thompson, J. K. (1997). Body image and body shape ideals in magazines: exposure, awareness, and internalization. Sex Roles, 37, 701-721. http://dx.doi.org/10.1007/BF02936336.

Daniel, S., \& Bridges, S. K. (2010). The drive for muscularity in men: media influences and objectification theory. Body Image, 7, 32-38. http://dx.doi.org/10. 1016/j.bodyim.2009.08.003.

Downey, C. A., Reinking, K. R., Gibson, J. M., Cloud, J. A., \& Chang, E. C. (2014). Perfectionistic cognitions and eating disturbance: distinct mediational models for males and females. Eating Behaviors, 15, 419-426. http://dx.doi.org/10.1016/j.eatbeh.2014.04.020.

Enders, C. K., \& Bandalos, D. L. (2001). The relative performance of full information maximum likelihood estimation for missing data in structural equation models. Structural Equation Modeling, 8, 430-457. http://dx.doi.org/10.1207/S15328007SEM0803_5.

Espinoza, P., Penelo, E., \& Raich, R. M. (2013). Prevention programme for eating disturbances in adolescents. Is their effect on body image maintained at 30 months later? Body Image, 10, 175-181. http://dx.doi.org/10.1016/j.bodyim.2012.11.004.

European Commission, Digital Agenda Scoreboard. (2013). Life online: Digital agenda scoreboard 2012. Retrieved from http://ec.europa.eu/digital-agenda/ sites/digital-agenda/files/scoreboard_life_online.pdf.

Field, A. E., Camargo, C. A., Taylor, C. B., Berkey, C. S., Roberts, S. B., \& Colditz, G. A. (2001). Peer, parent, and media influences on the development of weight concerns and frequent dieting among preadolescent and adolescent girls and boys. Pediatrics, 107, 54-60. http://dx.doi.org/10.1542/peds.107.1.54.

Forbush, K., Heatherton, T. F., \& Keel, P. K. (2007). Relationships between perfectionism and specific disordered eating behaviors. International Journal of Eating Disorders, 40, 37-41. http://dx.doi.org/10.1002/eat.20310.

Francisco, R., Alarcão, M., \& Narciso, I. (2011). Assessment of risk factors for the development eating disorders: development and validation study of the Portuguese version of the McKnight Risk Factor Survey IV. Revista Iberoamericana de Diagnóstico e Avaliação Psicológica, 32(2), $143-170$.

Francisco, R., Narciso, I., \& Alarcão, M. (2012). Body image (dis)satisfaction among Portuguese adolescents and adults: contribution to the validation process of the Contour Drawing Rating Scale. Revista Iberoamericana de Diagnóstico y Evaluación Psicológica, 34(1), 61-88.

Francisco, R., Narciso, I., \& Alarcão, M. (2013). Individual and relational risk factors for the development of eating disorders in adolescent aesthetic athletes and general adolescents. Eating and Weight Disorders, 18, 403-411. http://dx.doi.org/10.1007/s40519-013-0055-6.

Francisco, R., Oliveira, L., Santos, R., \& Novo, R. (2011). Portuguese version of EAT-26 (version for research). Lisboa: Universidade de Lisboa.

Francisco, R., Santos, R., Oliveira, L., \& Novo, R. (2011). Portuguese version of SATAQ-R (version for research). Lisboa: Universidade de Lisboa.

Frederick, D. A., Buchanan, G. M., Sadehgi-Azur, L., Peplau, L. A., Haselton, M. G., \& Berezovskaya, A. (2007). Desiring the muscular ideal: men's body satisfaction in the United States, Ukraine, and Ghana. Psychology of Men and Masculinity, 8, 103-117. http://dx.doi.org/10.1037/1524-9220.8.2.103.

Gandarillas, A., Zorrilla, B., Sepúlveda, A. R., \& Muñoz, P. E. (2003). Trastornos del comportamiento alimentario: Prevalencia de casos clínicos en mujeres adolescentes de la Comunidad de Madrid. In Documentos Técnicos de Salud Pública (Vol. 85). Retrieved November 8, 2013, from http://www. publicaciones-isp.org/productos/d085.pdf.

Garner, D. M. (1991). Eating Disorder Inventory-2 manual. Odessa: Psychological Assessment Resources.

Garner, D. M. (1998). EDI-2: Inventario de trastornos de la conducta alimentaria. Manual. Madrid: TEA Ediciones.

Garner, D. M., Olmsted, M. P., Bohr, Y., \& Garfinkel, P. E. (1982). The eating attitudes test: psychometric features and clinical correlates. Psychological Medicine, 12, 871-878. http://dx.doi.org/10.1017/S0033291700049163.

González, M., Penelo, E., Gutiérrez, T., \& Raich, R. M. (2011). Disordered eating prevention programme in schools: a 30-month follow-up. European Eating Disorders Review, 19, 349-356. http://dx.doi.org/10.1002/erv.1102. 
Graham, J. W. (2009). Missing data analysis: making it work in the real world. Annual Review of Psychology, 60, 549-576. http://dx.doi.org/10.1146/annurev. psych.58.110405.085530.

Gustafsson, S. A., Edlund, B., Kjellin, L., \& Norring, C. (2009). Risk and protective factors for disturbed eating in adolescent girls: aspects of perfectionism and attitudes to eating and weight. European Eating Disorders Review, 17, 380-389. http://dx.doi.org/10.1002/erv.930.

Halliwell, E., \& Harvey, M. (2006). Examination of a sociocultural model of disordered eating among male and female adolescents. British Journal of Health Psychology, 11, 235-248. http://dx.doi.org/10.1348/135910705X39214.

Hofstede, G. (2001). Culture's consequences: Comparing values, behaviors, institutions, and organizations across nations. Thousand Oaks, CA: Sage Publications. Hofstede, G., Hofstede, G. J., \& Minkov, M. (2010). Cultures and organizations: Software of the mind. Revised and expanded (3rd ed.). New York: McGraw-Hill. Hollingshead, A. B. (2011). Four factor index of social status. Yale Journal of Sociology, 8, $21-51$.

Holmqvist, K., \& Frisén, A. (2010). Body dissatisfaction across cultures: findings and research problems. European Eating Disorders Review, 18, 133-146. http://dx.doi.org/10.1002/erv.965.

Hu, L.-T., \& Bentler, P. (1999). Cutoff criteria for fit indexes in covariance structure analysis: conventional criteria versus new alternatives. Structural Equation Modeling, 6, 1-55. http://dx.doi.org/10.1080/10705519909540118.

Jones, D. C., Vigfusdottir, T. H., \& Yoonsun, L. (2004). Body image and the appearance culture among adolescent girls and boys: an examination of friend conversations, peer criticism, appearance magazines, and the internalization of appearance ideals. Journal of Adolescent Research, 19, 323-339. http://dx. doi.org/10.1177/0743558403258847.

Kayano, M., Yoshiuchi, K., Al-Adawi, S., Viernes, N., Dorvlo, A. S. S., Kumano, H., et al. (2008). Eating attitudes and body dissatisfaction in adolescents: crosscultural study. Psychiatry \& Clinical Neurosciences, 62, 17-25. http://dx.doi.org/10.1111/j.1440-1819.2007.01772.x.

Keel, P. K., \& Forney, K. J. (2013). Psychosocial risk factors for eating disorders. International Journal of Eating Disorders, 46, 433-439. http://dx.doi.org/10. 1002/eat.22094.

Keel, P. K., Klump, K. L., Leon, G. R., \& Fulkerson, J. A. (1998). Disordered eating in adolescent males from a school-based sample. International Journal of Eating Disorders, 23, 125-132. http://dx.doi.org/10.1002/(SICI)1098-108X(199803)23:2<125::AID-EAT2>3.0.CO;2-M.

Kjelsås, E., Bjørnstrøm, C., \& Götestam, K. G. (2004). Prevalence of eating disorders in female and male adolescents (14-15 years). Eating Behaviors, 5, 13-25. http://dx.doi.org/10.1016/S1471-0153(03)00057-6.

Knauss, C., Paxton, S. J., \& Alsaker, F. D. (2008). Body dissatisfaction in adolescent boys and girls: objectified body consciousness, internalization of the media body ideal and perceived pressure from media. Sex Roles, 59, 633-643. http://dx.doi.org/10.1007/s11199-008-9474-7.

Lawler, M., \& Nixon, E. (2011). Body dissatisfaction among adolescent boys and girls: the effects of body mass, peer appearance culture and internalization of appearance ideals. Journal of Youth \& Adolescence, 40, 59-71. http://dx.doi.org/10.1007/s10964-009-9500-2.

Levine, M. P., \& Smolak, L. (2002). Body image development in adolescence. In T. Cash, \& T. Pruzinsky (Eds.), Body image: A handbook of theory, research and clinical practice (pp. 74-81). New York: The Guilford Press.

Lunner, K., Werthem, E. H., Thompson, J. K., Paxton, S. J., McDonald, F., \& Halvaarson, K. S. (2000). A cross-cultural examination of weight-related teasing, body image, and eating disturbance in Swedish and Australian samples. International Journal of Eating Disorders, 28, 430-435. http://dx.doi.org/10.1002/ 1098-108X(200012)28:4<430::AID-EAT11>3.0.CO;2-Y.

Mautner, R. D., Owen, S. V., \& Furnham, A. (2000). Cross-cultural explanations of body image disturbance in Western cultural samples. International Journal of Eating Disorders, 28, 165-172. http://dx.doi.org/10.1002/1098-108X(200009)28:2<165::AID-EAT5>3.0.CO;2-G.

Muthén, L. K., \& Muthén, B. O. (1998-2012). Mplus user's guide (7th ed.). Los Angeles, CA: Muthén \& Muthén.

Pocinho, M. (2000). Peso, insatisfação corporal, dietas e patologia alimentar: Um contributo para o estudo das suas relações (Unpublished master's thesis). Coimbra: Instituto Superior Miguel Torga.

Presnell, K., Bearman, S. K., \& Stice, E. (2004). Risk factors for body dissatisfaction in adolescent boys and girls: a prospective study. International Journal of Eating Disorders, 36, 389-401. http://dx.doi.org/10.1002/eat.20045.

Privitera, G. J. (2008). The psychological dieter: It's not all about the calories. Lanham, MD: University Press of America.

Ricciardelli, L. A., \& McCabe, M. P. (2004). A biopsychosocial model of disordered eating and the pursuit of muscularity in adolescent boys. Psychological Bulletin, 130, 179-205. http://dx.doi.org/10.1037/0033-2909.130.2.179.

Rodgers, R., Chabrol, H., \& Paxton, S. J. (2011). An exploration of the tripartite influence model of body dissatisfaction and disordered eating among australian and french college women. Body Image, 8, 208-215. http://dx.doi.org/10.1016/j.bodyim.2011.04.009.

Rosenberg, M. (1965). Society and the adolescent self-image. Princeton: Princeton University Press.

Sheffield, J. K., Tse, K. H., \& Sofronoff, K. (2005). A comparison of body-image dissatisfaction and eating disturbance among Australian and Hong Kong women. European Eating Disorders Review, 13, 112-124. http://dx.doi.org/10.1002/erv.641.

Smolak, L., Levine, M., \& Thompson, J. K. (2001). The use of the sociocultural attitudes towards appearance questionnaire with middle school boys and girls. International Journal of Eating Disorders, 29, 216-223. http://dx.doi.org/10.1002/1098-108X(200103)29:2<216::AID-EAT1011>3.0.CO;2-V.

Soh, N. L., Touyz, S. W., \& Surgenor, L. J. (2006). Eating and body image disturbances across cultures: a review. European Eating Disorders Review, 14, 54-65. http://dx.doi.org/10.1002/erv.678.

Sorrells, K. (2012). Intercultural communication: Globalization and social justice. Thousand Oaks: Sage Publications.

Stice, E., Presnell, K., \& Spangler, D. (2002). Risk factors for binge eating onset in adolescent girls: a 2-year prospective investigation. Health Psychology, 21, 131-138. http://dx.doi.org/10.1037/0278-6133.21.2.131.

Stice, E., Schupak-Neuberg, E., Shaw, H. E., \& Stein, R. I. (1994). Relation of media exposure to eating disorder symptomatology: an examination of mediating mechanisms. Journal of Abnormal Psychology, 103, 836-840. http://dx.doi.org/10.1037/0021-843X.103.4.836.

Stice, E., \& Shaw, H. (2002). Role of body dissatisfaction in the onset and maintenance of eating pathology: a synthesis of research findings. Journal of Psychosomatic Research, 53, 985-993. http://dx.doi.org/10.1016/S0022-3999(02)00488-9.

Stice, E., \& Whitenton, K. (2002). Risk factors for body dissatisfaction in adolescent girls: a longitudinal investigation. Developmental Psychology, 38, 669-678. http://dx.doi.org/10.1037/0012-1649.38.5.669.

Striegel-Moore, R. H., \& Bulik, C. M. (2007). Risk factors for eating disorders. American Psychologist, 62, 181-198. http://dx.doi.org/10.1037/0003-066X.62.3. 181.

Thompson, M., \& Gray, J. J. (1995). Development and validation of a new body-image assessment scale. Journal of Personality Assessment, 64, 258-269. http://dx.doi.org/10.1207/s15327752jpa6402_6.

Thompson, J., Heinberg, L. J., Altabe, M. N., \& Tantleff-Dunn, S. (1999). Exacting beauty: Theory, assessment, and treatment of body image disturbance. Washington: American Psychological Association.

Tiggemann, M., Verri, A., \& Scaravaggi, S. (2005). Body dissatisfaction, disordered eating, fashion magazines, and clothes: a cross-cultural comparison between Australian and Italian young women. International Journal of Psychology, 40, 293-302. http://dx.doi.org/10.1080/00207590444000311.

Wade, T., \& Tiggemann, M. (2013). The role of perfectionism in body dissatisfaction. Journal of Eating Disorders, 1, 2-7. http://dx.doi.org/10.1186/2050-2974$1-2$.

Wertheim, E. H., Paxton, S. J., \& Tilgner, L. (2004). Test-retest reliability and construct validity of Contour Drawing Rating Scale scores in a sample of early adolescent girls. Body Image, 1, 199-205. http://dx.doi.org/10.1016/S1740-1445(03)00024-X. 